\title{
Vernonia amygdalina Leaf Extract Abates Oxidative Hepatic Damage and Inflammation Associated with Nitrobenzene in Rats
}

\author{
Johnson O. Oladele ${ }^{1, *}$, Oyedotun M. Oyeleke ${ }^{1}$, Blessing O. Akindolie ${ }^{1}$, Boyede D. \\ Olowookere $^{1}$, and Oluwaseun T. Oladele ${ }^{2}$ \\ ${ }^{1}$ Department of Chemical Sciences, Faculty of Science, Kings University, Ode-Omu, Osun State, Nigeria $;^{2}$ Phytomedicine and Toxicology \\ Laboratories, Department of Biochemistry, Faculty of Basic and Applied Sciences, Osun State University, Osogbo, Nigeria.
}

Received: March 30, 2020; Revised: September 16, 2020; Accepted: September 17, 2020

\begin{abstract}
Liver diseases have been documented to have great influence on the global burden of mortality and morbidity. This study was conducted to investigate the ability of Vernonia amygdalina to protect against hepatic damage and inflammation in nitrobenzene rat model of hepatotoxicity. Thirty male Wistar strain albino rats were used for this study. Rats were exposed to $100 \mathrm{mg} / \mathrm{kg}$ body weight (BW) of nitrobenzene via oral administration and treated with 200 and $400 \mathrm{mg} / \mathrm{kg}$ BW of methanol leaf extract of Vernonia amygdalina (MLVA) and $400 \mathrm{mg} / \mathrm{kg}$ BW of Vitamin E for 14 consecutive days. Nitrobenzene significantly $(\mathrm{P}<0.05)$ induced hepatic damage with marked serum level of aspartate aminotransferase (AST), alanine aminotransferase (ALT), acid phosphatase (ACP) and alkaline phosphatase (ALP). Furthermore, nitrobenzene mediated oxidative stress and lipid peroxidation with a significant increase in hepatic level of malondialdehyde (MDA), hydrogen peroxide $\left(\mathrm{H}_{2} \mathrm{O}_{2}\right)$, with concomitant decrease in level of reduced glutathione (GSH), Catalase (CAT) and Superoxide dismutase (SOD). Similarly, inflammation was observed in nitrobenzene-treated rats with elevated level of nitric oxide (NO) and myeloperoxidase (MPO). However, treatment with the chosen doses of MLVA and Vitamin E significantly reversed all the nitrobenzene-associated hepatic damage, oxidative stress, lipid peroxidation, inflammation and altered antioxidant defence system. Taken together, MLVA exhibited hepatoprotection which may be beneficial for the treatment and management of liver diseases or other related disorders via protecting the structural integrity of the liver, antioxidant, antiinflammatory mechanisms.
\end{abstract}

Keywords: Hepatotoxicity, oxidative stress, Inflammation, Nitrobenzene, Vernonia amydalina

\section{Introduction}

Liver diseases have been reported to have huge impact on the global burden of mortality and morbidity (Lozano et al., 2010; Murray et al., 2010). In 2010, Global Burden of Disease (GDB) documented that liver cirrhosis caused more than one million deaths $(1,030,800$ deaths representing $2.0 \%$ of all deaths, $1.4 \%$ of all deaths of women and $2.4 \%$ of all deaths of men) and 31,027,000 Disability Adjusted Life Years (DALYs) $(1.2 \%$ of all DALYs, $0.8 \%$ of all DALYs for women, $1.6 \%$ of all DALYs for men). Systematic analysis of Mokdad et al., (2014) also documented that about 2 million deaths annually are caused by liver diseases. In the study, hepatocellular carcinoma and viral hepatitis caused about 1 million deaths while complications of cirrhosis were responsible for about 1 million deaths globally. The Middle East, Caribbean, Latin America and North Africa are the regions that showed the highest percentage of deaths due to liver related diseases (Briggs, 2003).

Among other factors, exposure to toxic chemicals from industrial and occupational sources has been implicated to play a pivotal role in the aetiology and pathogenesis of liver diseases (Briggs, 2003). Hepatotoxins are toxic foreign compounds capable of damaging the liver structural and physiological functions leading to severe adverse effects on the liver. Nitrobenzene is an example of such hepatotoxicants; it is an important chemical material widely applied in national defence and the industries of printing and dyeing, plastics, pesticide and pharmaceutical. Nitrobenzene is considered a dangerous air pollutant and has proven to be an animal carcinogen. According to the 1986 Cancer guide lines, nitrobenzene has been classified as a group B2 chemical, i.e. a likely human carcinogen (Cattley et al., 1994). Intermediates such as nitrosobenzene and phenylhydroxylamine $(\mathrm{PH})$ are produced during metabolism of nitrobenzene. These intermediates have been documented to play a pivotal role in the process of nitrobenzene carcinogenesis (Howard et al., 1983). Following accidental nitrobenzene poisoning in humans, the highest concentration was found in the liver, brain, blood and stomach (International Programme on Chemical Safety, 2003). Akinloye et al (2014) have documented the hepatotoxicity effects of nitrobenzene.

Phytochemicals are naturally occurring compounds regarded as one of the important origins of biologically active natural products (Koksal et al., 2009). The reported biological and pharmacological activities such as anticarcinogenic, anti-inflammatory, and antioxidant, and

\footnotetext{
* Corresponding author e-mail: oladelejohn2007@gmail.com, jo.oladele@kingsuniversity.edu.ng.
} 
antimutagenic activities of these isolated active compounds from plants have awaken research interest towards development of more potent drugs to combat various diseases (Wu et al., 2008; Yang et al., 2006). The bioactive compounds that have been recorded to be present in a number of plants may produce medicinal effects for in treatment of reproductive related disorders.

Vernonia amygdalina, commonly known as bitter leaf, is a medicinal plant with several health benefits. The documented phytochemical constituents of various fractions of Vernonia amygdalina includes epivernodalol, sesquiterpene lactones, elemanolide (Erasto et al., 2006), edotides (Izeybigie, 2003), terpenes, steroids, coumarins, flavonoids, phenolic acids, lignans, xanthones and anthraquinone (Cimanga et al., 2004), saponins and alkaloids (Muraina et al., 2010). These phytochemical constituents have been reported to be responsible for a number of medicinal valves of the plant such as antimicrobial activities (Iwu et al., 1999), antioxidant properties (Adesanoye and Farombi, 2010), and antiinflammatory (Ibrahim et al., 2010). The anti-malarial activity of Vernonia amygdalina essentially against $P$. falciparum was reported to be due to the presence of sesquiterpenes lactones compounds which include vernolide, vernodalin, hydroxy vernolides and the steroid related constituents, vernoniosid B1 and vernonoid B1 (Magboul et al., 2008).

Therefore, the aim of this study is to investigate the cytotoxic effects of nitrobenzene in the liver of Wistar albino rats via evaluation of liver function tests, oxidative hepatic damage markers histopathological indices and cytoarchitecture of the hepatic cells. Moreover, to investigate the protective effect of methanol leaf extract of Vernonia amygdalina against the nitrobenzene-induced hepatic damage. Vitamin E, a standard clinical medicine, is used to compare the protective activities of the extract.

\section{Materials and methods}

\subsection{Chemicals/ Reagents}

High purity (> 99.7\%) Nitrobenzene was obtained from BDH chemical Poole England. Vitamin E (Alpha Tocopherol) is a product of Embassy pharmaceuticals, Nigeria. Aspartate aminotransferase (AST), alanine aminotransferase (ALT), acid phosphatase (ACP) and alkaline phosphatase (ALP) enzyme diagnostic kits were obtained from Randox. Potassium iodide, Copper sulphate, hydrogen peroxide, $\mathrm{KCl}$, phosphate buffer salts: $\mathrm{Na}_{2} \mathrm{HPO}_{4}$ $12 \mathrm{H}_{2} \mathrm{O}$ and $1.19 \mathrm{~g} \mathrm{NaH_{2 }} \mathrm{PO}_{4} 2 \mathrm{H}_{2} \mathrm{O}$ are of analytical grade and were obtained from Analar BDH Limited, Poole, England. Bovine Serum Albumin (standard), 5', 5' dithiobis - (2-nitrobenzoic acid) (Ellman's reagent), epinephrine, reduced glutathione, 2 - nitro-5-thiobenzoic acid are products of Sigma-Aldrich Co. St Louis, Missouri, USA.

\subsection{Collection of Plant Material and Preparation of Extract}

Fresh leaves of Vernonia amygdalina were collected at the staff quarters in Kings University, Odeomu, Osun State. The leaf has been identified at IFE-Herbarium of Botany Department, Obafemi Awolowo University, Ile-Ife with voucher number. The Vernonia amygdalina leaves were washed and air-dried at room temperature in the
Biochemistry laboratory, Kings University, Nigeria and pulverized using an electric blender. The powdered leaf was defatted in n-hexane using Soxhlet apparatus. Thereafter, methanolic extract was prepared by soaking the defatted leaf in $90 \%$ methanol for 72 hours. The resulting mixture was then filtered, and the filtrate was concentrated on water bath. The concentrated extract was lyophilized using Bosch freeze drying machine. The full chemical identification and bioactive compounds of Vernonia amygdalina have been earlier reported by Oladunmoye et al (2019) using gas chromatography-mass spectrometry (GC-MS). The technique reveals methyl-2-O-benzyl-darabinofuranoside, phytol, hexadecanoic acid, ethyl ester, squalene and $9,12,15$, octadecatrienoic acid as the more abundant compounds (>85\% abundance) while N-[2(dimethylamino)-5-pyrimidinyl] benzene sulfonamide, 9, 12, 15 and octadecatrien-1-ol, p-Menth-4(8)-en-9-ol has the less abundance ( $<12 \%$ abundance) compounds.

\subsection{Experimental animals}

Thirty matured 4-5 months old male Wistar strain albino rats were used in the study. The rats were sourced and raised at the Biochemistry breeding colony of the Biochemistry unit, Department of Chemical Sciences, Kings University, Ode-Omu, Osun state, Nigeria. Animals were kept under ambient standard conditions $\left(25 \pm 2{ }^{\circ} \mathrm{C}\right.$ and relative humidity of $50 \pm 15 \%$ ) in stainless steel cages, and metabolic wastes were cleaned twice daily. The rats were allowed to acclimatize to these conditions for fourteen days and were exposed to 12 hrs daylight and darkness cycle, fed with commercially available rat pellet and water ad libitum. The experiment was carried out in accordance with current rules and guidelines that have been established for the care of the laboratory animals (NRC, 2011). The rats were randomised into five groups containing six rats each.

Group A: received distilled water daily and serve as the Control.

Group B: received $100 \mathrm{mg} / \mathrm{kg}$ Nitrobenzene orally.

Group C: received $100 \mathrm{mg} / \mathrm{kg}$ Nitrobenzene and 200 $\mathrm{mg} / \mathrm{kg}$ Vernonia amygdalina

Group D: received $100 \mathrm{mg} / \mathrm{kg}$ Nitrobenzene and 400 $\mathrm{mg} / \mathrm{kg}$ Vernonia amygdalina

Group E: Received $100 \mathrm{mg} / \mathrm{kg}$ Nitrobenzene and 400 $\mathrm{mg} / \mathrm{kg}$ Vitamin E

Treatments were administered to the rats orally for 14 consecutive days.

\subsection{Preparation of Serum}

The rats were sacrificed 24hrs after the last treatment and blood sample collected into clean, dry centrifuge tube. The blood was left for $10 \mathrm{~min}$ at room temperature to clot after which it was centrifuged at 4,000 rpm for $20 \mathrm{~min}$ in an MSC (Essex, UK) bench centrifuge. The clear supernatant (serum) was aspirated using a Pasteur pipette into clean, dry sample bottles and then stored at $4{ }^{\circ} \mathrm{C}$ for biochemical analyses.

\subsection{Preparation of liver homogenates}

The livers were immediately excised and blotted to remove blood stains. They were cleansed and rinsed in $1.15 \% \mathrm{KCl}$ on ice to remove haemoglobin, then weighed. They were then chopped into bits and homogenized in four volumes of the homogenizing buffer $(10 \mathrm{mM}$ potassium phosphate buffer, $\mathrm{pH}$ 7.4) using a Teflon homogenizer. 
The homogenates were centrifuged at $12,500 \mathrm{~g}$ for 15 minutes in a cold centrifuge $\left(4^{\circ} \mathrm{C}\right)$ to obtain the post mitochondrial fractions which were collected and used for biochemical analyses.

\subsection{Measurement of biochemical markers}

AST, ALT, ACP and ALP were measured by following the enzymes kits manufacturer's instructions (Randox). The protein content of the homogenates was determined using BSA as a standard in the protocol described by Lowry et al. (1951). Nitric oxide (NO) level was assessed by procedure reported by Green et al. (1982). Myeloperoxidase (MPO) activity in the homogenate was quantified following the method of Granell et al. (2003). Superoxide dismutase (SOD) activity was evaluated following the inhibition of adrenaline auto-oxidation in a basic milieu as described by Misra and Fridovich, (1972). Lipid peroxidation was evaluated by monitoring the level of MDA using procedure reported by Varshney and Kale (1990). The reduced GSH content in the brain samples was determined using the protocol reported by Buetler et al. (1963). Catalase (CAT) activity was determined following the protocol documented by Clairborne (1995) using hydrogen peroxide $\left(\mathrm{H}_{2} \mathrm{O}_{2}\right)$ as a substrate. Hydrogen peroxide generation was assayed oxidation of ferrous ions and sorbitol colour amplification system using the method of Wolff (1994).

\subsection{Histological Examination}

The livers were immediately fixed in $10 \%$ formalin and embedded in paraffin wax. Fine sections (7-9 mm thickness) of the livers were then dewaxed in xylene, hydrated in decreasing percentage of alcohol and stained with hematoxylin and eosin. The stained sections were observed under a Leitz microscope and their photomicrograph taken at X 100 with a Canon (Meville, NY) Power Shot G2 Digital Camera (Oladele et al., 2017).

\subsection{Statistical Analysis}

Results obtained were expressed as mean \pm standard deviation (mean $\pm \mathrm{SD}$ ) and analysed using one-way analysis of variance (ANOVA) with the aid of SPSS 22.0 computer software package (SPSS Inc; Chicago, U.S.A) to compare the experimental groups followed by Bonferroni's post-hoc test. Valves at $\mathrm{P}<0.05$ were considered significant.

\section{Results}

\subsection{MLVA enhances hepatic enzymes activities in nitrobenzene-induced hepatotoxicity in rats}

Figures 1 and 2 show that rats exposed to $100 \mathrm{mg} / \mathrm{kg}$ body weight of nitrobenzene (group B) showed a significant increase $(\mathrm{P}<0.05)$ serum concentration levels of ALT, AST, ACP and ALP as compared to the control (group A). This suggests injury to the liver membrane and alteration to liver physiological activities. These altered valves were reverted significantly $(\mathrm{P}<0.05)$ toward normal in a dose dependent manner in rats treated with 200 and $400 \mathrm{mg} / \mathrm{kg}$ body weight of MLVA or vitamin E (group C, D \& E respectively).

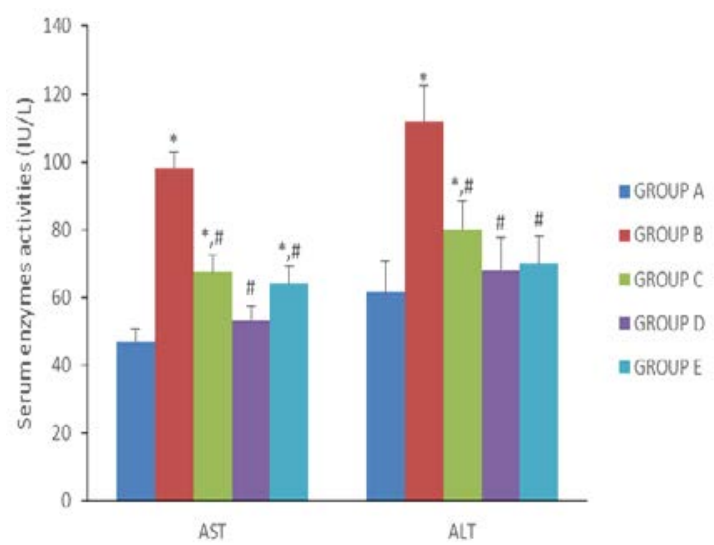

Figure 1: Effect of MLVA on aspartate aminotransferase (AST) and alanine aminotransferase (ALT) activities in rats treated with nitrobenzene.

Data are given as mean \pm SD of rats per group. $n=6$. MLVA: methanol leaf extract of Vernonia amygdalina, *: Values differ significantly from group A (control) $(\mathrm{P}<0.05)$. \#: Values differ significantly from group $\mathrm{B}$.

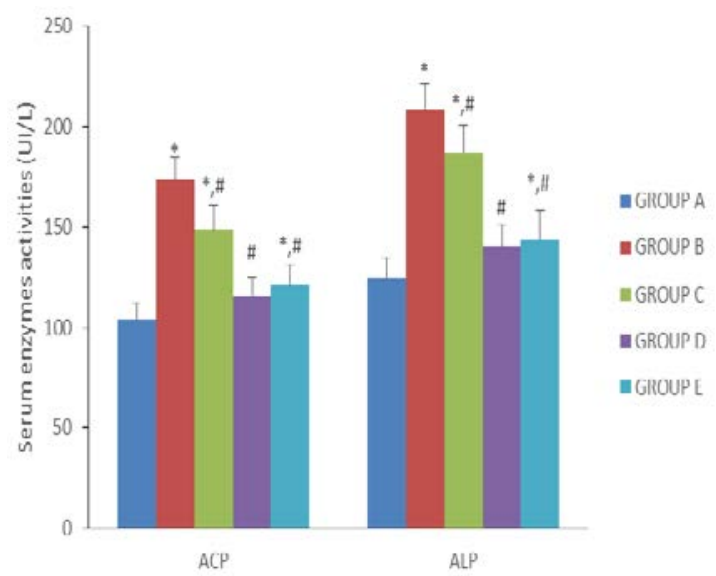

Figure 2: Effect of MLVA on acid phosphatase (ACP) and alkaline phosphatase (ALP) activities in rats treated with nitrobenzene.

Data are given as mean \pm SD of rats per group. $n=6$. MLVA: methanol leaf extract of Vernonia amygdalina, *: Values differ significantly from group A (control) $(\mathrm{P}<0.05)$. \#: Values differ significantly from group B.

\subsection{MLVA inhibits inflammatory activity in liver of rats treated with nitrobenzene}

The effects of MLVA on inflammation in liver of the experimental rats was evaluated by measuring MPO activities and NO concentration level. Rats administered nitrobenzene alone demonstrated a marked increase in NO level and MPO activities when compared with the control (Figure 3 and 4). However, treatment with of 200 and 400 $\mathrm{mg} / \mathrm{kg}$ of MLVA or Vitamin E significantly attenuated both NO and MPO levels in the liver when compared with control. 


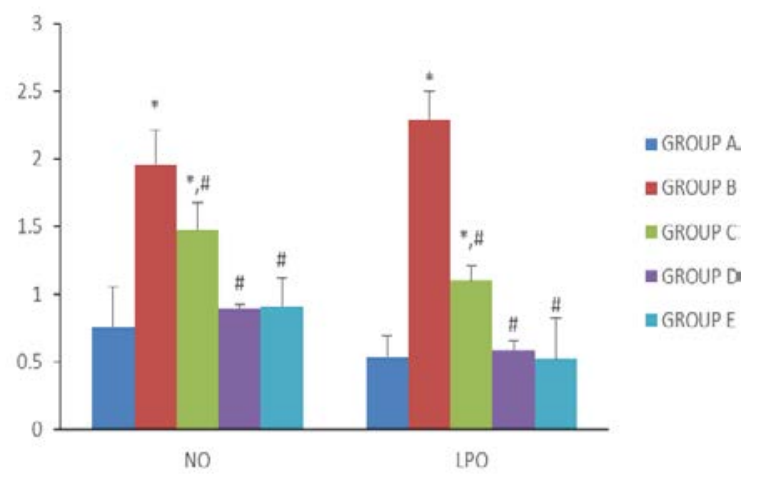

Figure 3: Effect of MLVA on nitric oxide (NO) and Lipid peroxidation (LPO) level in rats treated with nitrobenzene.

Lipid peroxidation ( $\mu$ mol MDA/mg protein); NO level (Unit/mg protein). Data are given as mean \pm SD of rats per group. $n=6$. MLVA: methanol leaf extract of Vernonia amygdalina, *: Values differ significantly from group A (control) $(\mathrm{P}<0.05)$. \#: Values differ significantly from group B.

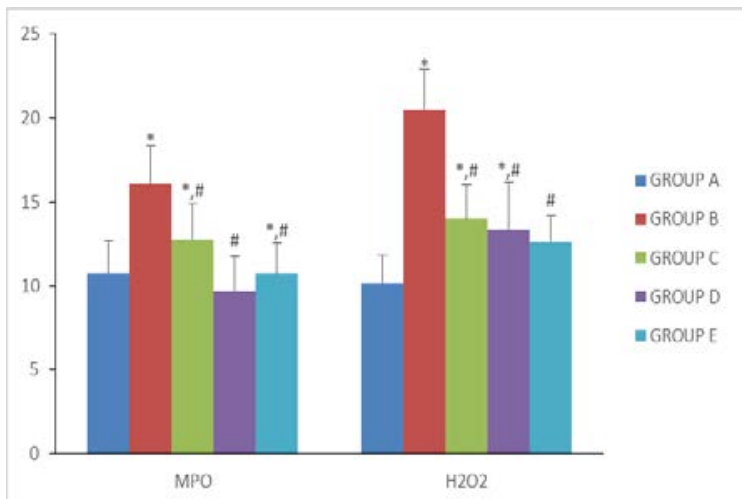

Figure 4: Effect of MLVA on myeloperoxidase (MPO) and hydrogen peroxide generation $\left(\mathrm{H}_{2} \mathrm{O}_{2}\right)$ levels in rats treated with nitrobenzene.

MPO activity (Units/mg protein); $\mathrm{H}_{2} \mathrm{O}_{2}$ ( $\mu$ mole/mg protein). Data are given as mean \pm SD of rats per group. $n=6$. MLVA: methanol leaf extract of Vernonia amygdalina, *: Values differ significantly from group A (control) $(\mathrm{P}<0.05)$. \#: Values differ significantly from group B.

\subsection{MLVA suppressed lipid peroxidation and oxidative} stress in liver of rats treated with nitrobenzene

Fig. 3 and 4 showed the results of hepatic oxidative stress biomarkers carried out in the experimental rats. There was a marked increase in MDA level (an index of lipid peroxidation) and $\mathrm{H}_{2} \mathrm{O}_{2}$ generation in rats administered nitrobenzene only when compared with the control group. Upon treatment with 200 and $400 \mathrm{mg} / \mathrm{kg}$ of MLVA or Vitamin E, there was a significant decrease ( $\mathrm{p}<$ 0.05 ) in both MDA and $\mathrm{H}_{2} \mathrm{O}_{2}$ generation levels in the livers.

\subsection{MLVA influenced reduced glutathione level and antioxidant enzymes activities in liver of rats treated with nitrobenzene}

Fig. 5-7 show the glutathione level and antioxidant activities of CAT and SOD in the liver of experimental rats. Administration of rat with nitrobenzene alone showed a significant decrease $(\mathrm{p}<0.05)$ in GSH level and decline in activities of CAT and SOD when compared with the control. However, treatment with 200 and $400 \mathrm{mg} / \mathrm{kg}$ of
MLVA or Vitamin E significantly increased the GSH level and enhanced all the enzymes.

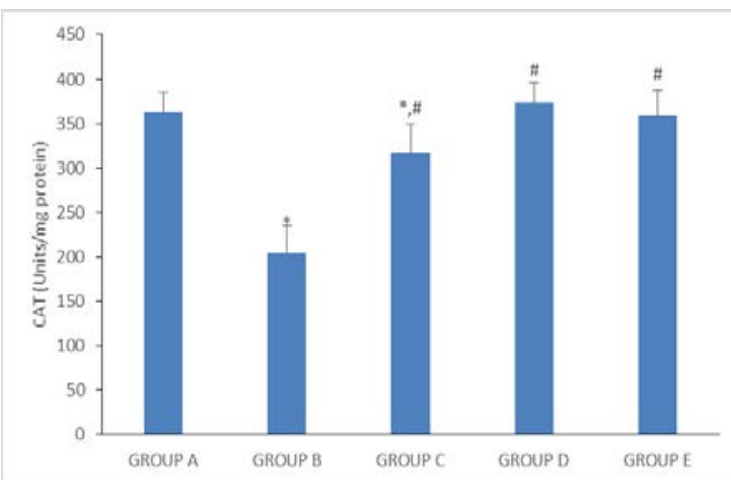

Figure 5: Effect of MLVA on catalase (CAT) activities in rats treated with nitrobenzene.

MPO activity (Units/mg protein); $\mathrm{H}_{2} \mathrm{O}_{2}$ ( $\mu$ mole/mg protein). Data are given as mean $\pm \mathrm{SD}$ of rats per group. $\mathrm{n}=6$. MLVA: methanol leaf extract of Vernonia amygdalina, *: Values differ significantly from group A (control) $(\mathrm{P}<0.05)$. \#: Values differ significantly from group B.

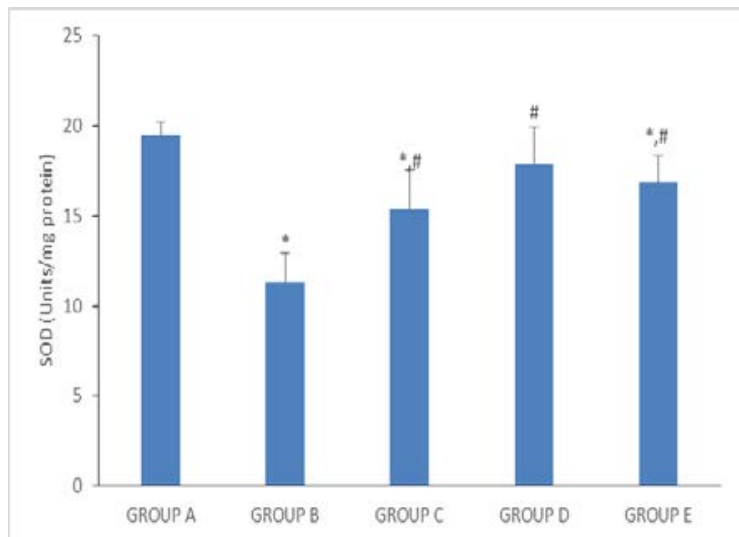

Figure 6: Effect of MLVA on superoxide dismutase (SOD) activities in rats treated with nitrobenzene.

MPO activity (Units/mg protein); $\mathrm{H}_{2} \mathrm{O}_{2}$ ( $\mu$ mole/mg protein). Data are given as mean $\pm \mathrm{SD}$ of rats per group. $\mathrm{n}=6$. MLVA: methanol leaf extract of Vernonia amygdalina, *: Values differ significantly from group A (control) $(\mathrm{P}<0.05)$. \#: Values differ significantly from group B.

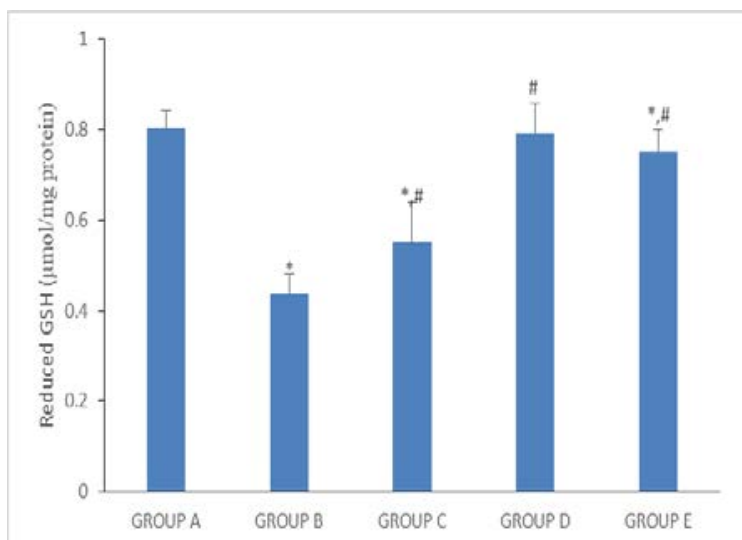

Figure 7: Effect of MLVA on reduced glutathione (GSH) content in rats treated with nitrobenzene.

Data are given as mean \pm SD of rats per group. $\mathrm{n}=6$. MLVA: methanol leaf extract of Vernonia amygdalina, *: Values differ significantly from group A (control) $(\mathrm{P}<0.05)$. \#: Values differ significantly from group B. 
3.5. Ameliorative effects of MLVA on histological alterations in liver sections of nitrobenzene-induced hepatotoxicity in rats

Fig. 8 shows the histological alterations seen with the light microscope in the liver sections of the experimental rats. The cytoarchitecture and morphology of liver of rats from control group appeared normal. However, obvious pathological lesions were observed in the liver sections of nitrobenzene group characterized by a mild loss of liver parenchyma, some mild derangement in the cellular profiles, haemorrhage and presence of inflammatory red cells within and around the central vein including the sinusoids as well as distorted hepatic vessels (red arrows). A, C and E group showed no altered panoramic morphological presentation accompanied by well outlined cellular profile as well as distinct hepatic structures.
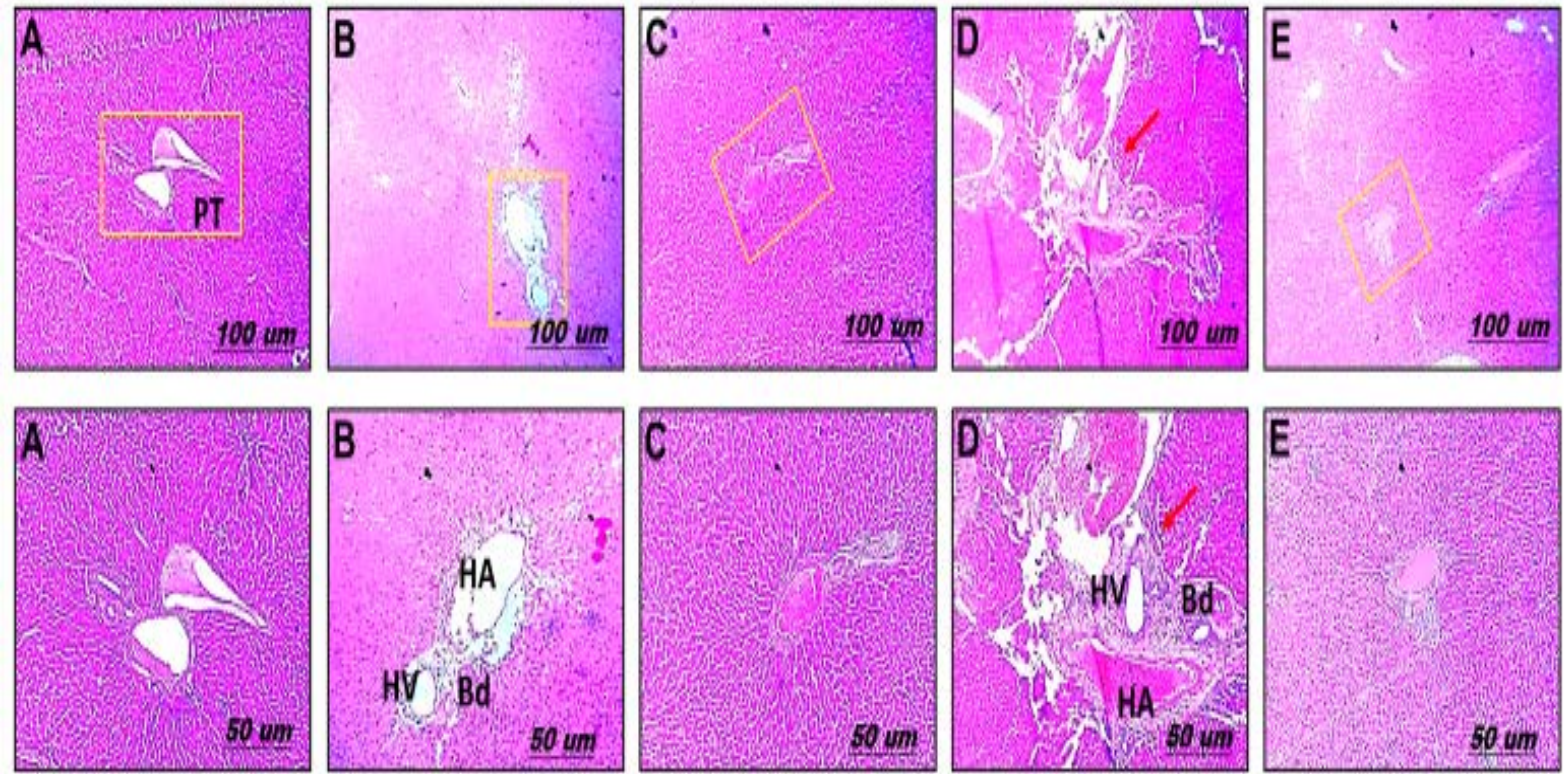

Figure 8: Photomicrographs of the panoramic views of liver general micromorphological presentations in Adult Wistar rats across the study groups. Hematoxylin and Eosin stain. The hepatic duct, Portal triad (PT) composed of the hepatic vein (HV) and artery (HA) as well as the bile duct (BD), the well distributed hepatocytes across the general cytoarchitecture are demonstrated across study groups A-E.

\section{Discussions}

Nitrobenzene is an industrial chemical widely used in the synthesis of aniline and other products such as dyes, analgesics, pesticides, pyroxylin compounds and shoes polishes. However, it has been reported to induce tumour in vital organs (including liver) in experimental animals (Cattley et al., 1994), thus classified as a group B2 toxicants which is likely to be human carcinogen (US EPA, 1996). Vernonia amygdalina is a medicinal plant with potential chemo-preventive activities. This study is designed to investigate the protective ability of methanol leaf extract of Vernonia amygdalina against nitrobenzeneinduced toxicities. The efficacy of the extract is compared with vitamin $\mathrm{E}$.

In this study, we demonstrated that exposure of rats to nitrobenzene resulted in a marked increase in the serum levels of ALT, ACP, AST and ALP which is indicative of hepatocellular damage, as previously documented (Oladele and Oyewole, 2017; Oladele et al., 2017; Oyewole et al., 2017). The significant increase in the hepatic markers in the serum of the experimental rats could be as a result of release of these compartmentalized enzymes into the blood circulatory system due to rupture of the membrane and cellular damage caused by nitrobenzene (Oladele et al., 2020a; Essawy et al., 2019). Treatment with graded doses of methanol leaf extract of Vernonia amygdalina or Vitamin E significantly reversed the elevated activities of these enzymes. This effect might be due to the extract's ability to mitigate free radical mediated oxidative damage in the hepatocytes (Alamoudi, 2019). Also, Vitamin E has been reported to have antioxidant and cyto-protective activities (Oladele et al., 2020c).

Biotransformation of nitrobenzene has been reported to generate free radicals and reactive oxygen species which, in turn, alters the antioxidant system and finally results into oxidative stress and macromolecule damage (Akinloye et al., 2014). In this study, exposure of rats to nitrobenzene caused a marked increase in the level of hepatic hydrogen peroxide $\left(\mathrm{H}_{2} \mathrm{O}_{2}\right) \cdot \mathrm{H}_{2} \mathrm{O}_{2}$ can be rapidly decomposed into oxygen and water, and this may produce hydroxyl radicals ( $\mathrm{OH}$ ) that can initiate lipid peroxidation and cause DNA damage (Sahreen et al., 2011). However, treatment with graded doses of methanol leaf extract of Vernonia amygdalina or Vitamin E significantly mitigated the hydrogen peroxide generation in the liver. This can be attributed to the antioxidant and free radical scavenging effects of the extract.

Lipid peroxidation has been reported to play a critical role in cancer development (carcinogenesis) (Banakar et al., 2004). The process produces some byproducts which are highly toxic to the cells. These toxic byproducts include malondialdehyde (MDA) and 4-hydroxynonenal. They can easily attack cellular targets such as proteins and DNA leading to genetic mutations and ultimately to carcinogenicity (de Zwart et al., 1999). In this study, administration of nitrobenzene into rats caused a significant increase in lipid peroxidation as indicated by marked level of malondialdehyde (MDA) in the liver. However, groups treated with graded doses of methanol leaf extract of Vernonia amygdalina or Vitamin E showed 
a significant reduction in level of malondialdehyde when compared to the animals treated with nitrobenzene only. The observed decrease in lipid peroxidation in rats treated with methanol leaf extract of Vernonia amygdalina could be due to its ability to scavenge the hydroxyl and peroxyl radicals.

Similarly, nitrobenzene induced inflammation in the liver of the experimental rats with evidence of marked increase in the level of nitric oxide (NO) and myeloperoxidase (MPO) activity. This observation indicates involvement of aggravated inflammatory response in nitrobenzene-induced hepatotoxicity. NO is a toxic defense molecule synthesized by inducible nitric oxide synthase (iNOS) in many cell types involved in immunity and inflammation. Treatment the various doses of methanol leaf extract of Vernonia amygdalina or Vitamin E significantly inhibited the inflammatory process in the hepatic cells. This agrees with the previous report that the extract has anti-inflammatory properties.

One of the primary functions of antioxidant and free radical scavenging enzymes such as CAT, and SOD is to protect biological cells against free radical attacks and oxidative stress. This study revealed that administration of nitrobenzene to rats caused a significant decrease in these enzymes activities. The observed reduction in these enzymes activities may have been a result of overwhelming detoxification activities of the enzymes by conjugating with the free radicals/ROS and other toxic byproducts to enhance their excretion. However, there was a marked increase in CAT, and SOD in rats treated with graded doses of methanol leaf extract of Vernonia amygdalina or Vitamin E. Many scientific reports have proven that one of the protective mechanism of actions of plant extracts is via upregulation of these endogenous antioxidant enzymes (Farombi et al., 2019, Oladele et al., 2020b).

Similarly, a depletion in the GSH level was observed in the nitrobenzene treated rats. This significant decrease in GSH level might have been due to GSH usage by the detoxifying enzyme (GST) and may be responsible for increase in lipid peroxidation (Bansal et al., 2005; Mohamed et al., 2018). Free radical mediated tissue damage can be inhibited or alleviated by ensuring the redox balance to decrease the oxidative stress status. On the other hand, rats treated with Vernonia amygdalina or Vitamin E display a marked increase in GSH level. This agrees with previous report of Oladele et al (2020c) who documented that Vernonia amygdalina caused a reversal to decreased GSH level induced by nitrobenzene. This suggests that the protective effect of Vernonia amygdalina extract involves the maintenance of antioxidant capacity in preventing the hepatic cells against oxidative damage.

\section{Conclusion}

This study demonstrated that nitrobenzene induced liver injury which was followed by significant increase in serum activities level of ALT, AST, ACP. Also, inflammation was observed in the liver with increased level of NO and MPO with concomitant increased level of MDA confirming lipid peroxidation. Furthermore, there is a significant decreased in reduced GSH level, CAT and SOD activities indicating oxidative stress in the liver tissue. However, treatment with graded doses of methanol leaf extract of Vernonia amygdalina reversed all the nitrobenzene-associated hepatic damage, oxidative stress, lipid peroxidation, inflammation and altered antioxidant defence system. Similarly, histological observations showed that the extract was capable of not only preventing but actually reversing the patho-morphological changes of nitrobenzene-induced liver injury such as changes in fat deposition, mild loss of liver parenchyma, haemorrhage and inflammatory cell infiltration. Taken together, methanol leaf extract of Vernonia amydalina exhibited hepatoprotection which may be beneficial for the treatment and management of liver diseases or other related disorders via protecting the structural integrity of the liver, antioxidant, anti-inflammatory mechanisms.

\section{References}

Adesanoye OA, and Farombi EO. 2010. Hepatoprotective effects of $V$. amygdalina (Astereaceae) in rats treated with carbon tetrachloride. Exp. Toxicol. Pathol., 62: 197-206.

Akinloye OA, Somade OT, Akindele AS, Adelabu KB, Elijah FH, and Adewumi OJ. 2014. Anticlastogenic and hepatoprotective Properties of ginger (zingiber officinale) Extract against nitrobenzene-induced Toxicity in rats. Rom. J. Biochem., 51: 3-15

Alamoudi WM. 2019. An Evaluation of the Antioxidant Properties of Propolis against Fenvalerate-induced Hepatotoxicity in Wistar Rats. Jordan Journal of Biological Sciences. 12: 581 588

Banakar MC, Paramasivan SK, Chattopadhyay MB. 2004. 1alpha, 25-dihydroxyvitamin D3 prevents DNA damage and restores antioxidant enzymes in rat hepatocarcinogenesis induced by diethylnitrosamine and promoted by phenobarbital. World $J$ Gastroenterol. 10: 1268-75.

Bansal AK, Bansal M, Soni G. 2005. Protective role of Vitamin E pre-treatment on $\mathrm{N}$-nitrosodiethylamine induced oxidative stress in rat liver. Chem Biol Interact. 156: 101-11.

Briggs D. 2003. Environmental pollution and the global burden of disease. British Med. Bulletin. 68:1-24

Buetler E, Duron O and Kelly BM. 1963. Improved method for the determination of blood glutathione. Journal of Laboratory and Clinical Medicine, 61: 882-888.

Cattley RC, Everitt JI, and Gross EA. 1994. Carcinogenicity and toxicity of inhaled nitrobenzene in B6C3F1mice and F344 and CD rats. Toxicol. Sci., 22: 328-340.

Cimanga RK, Tona L, Mesia K, Musuamba CT, De Bruyne T, Apers S, Hernan N, Miert VS, Pieters L, Totte J, and Vlietink, AJ. 2004. In vitro antiplasmodia acivity of extravts and fractions of seven medicinal plants used in the democratic republic of Congo. J. Ethnopharmacol. 93: 27-32.

Clairborne A. 1995. Catalase activity. Handbook of Methods for Oxygen Radical Research. CRC Press, Florida.

de Zwart LL, Meerman JH, Commandeur JN, et al. 1999. Biomarkers of free radical damage applications in experimental animals and in humans. Free Radic Biol Med 26: 202-26.

Erasto P, Grierson DS, Afolayan AJ. 2006. Bioactive sesquiterpenes lactones from the leaves of $V$. amygdalina. $J$. Ethnopharmacol., 106: 117-120.

Essawy AE, Lamfon HA, Al Harbi AB, Ali AM and Lamfon NA. 2019. The Effect of Salvia officinalis Extract on Alleviating Oxidative Stress and Hepatic Dysfunction Induced by Carbon Tetrachloride in Mice. Jordan Journal of Biological Sciences. 12: $403-408$ 
Farombi EO, Awogbindin IO, Farombi TH, Oladele JO, Izomoh ER, Aladelokun OB, Ezekiel IO, Adebambo OI, and Abah VO. 2019. Neuroprotective role of kolaviron in striatal redoinflammation associated with rotenone model of Parkinson's disease. Neurotoxicology. 73:132-141.

Granell S, Gironella M, Bulbena O, Panes J, Mauri M, Sabater L, Aparisi L, Gelpi E, and Closa D. 2003. Heparin mobilizes xanthine oxidase and induces lung inflammation in acute pancreatitis. Crit. Care Med., 31: 525-530.

Green LC, Wagner DA, Glogowski J, Skipper PL, Wishnok JS, and Tannenbaum SR. 1982. Analysis of nitrate, nitrite, and [15N] nitrate in biological fluids. Anal. Biochem., 126: 131-138.

Howard PC, Beland FA, and Cerniglia CE. 1983. Reduction of the carcinogen 1-nitropyrene to1-aminopyrene by the rat intestinal bacteria. Carcinogenesis, 4: 985-990.

Ibrahim G, Abdurahman EM, Ibrahim H, and Ibrahim NO. 2010. Comparative cytomormological studies on the studies of $\mathrm{V}$. amygdalina Del. and V. Kotschyama. Nig. J. Botany, 23 (1): 133142.

International Programme on Chemical Safety (IPCS). Nitrobenzene environmental health criteria 230. Geneva: WHO; 2003

Iwu MW, Duncan AR, and Okunji CO. 1999. New Antimicrobials of Plant Origin. In Perspectives on New Crops and New Uses. J. Janick (Ed). ASHS Press, Alexandria, VA.

Izeybigie EB. 2003. Discovery of water soluble anticancer agent (Edotides) from a vegetable found in Benin City, Nigeria. Exper. Bio. Med., 228: 293-299.

Koksal E, Gulcin I, Beyza S, Sarikaya O, Bursal E. 2009. In vitro antioxidant activity of silymarin. Journal of Enzyme Inhibition and Medicinal Chemistry 24(2): 395-404.

Lowry OH, Rosenbrough NJ, Farr AL, and Randall RJ. 1951. Protein measurement with the Folin phenol reagent. Journal of Biological Chemistry 193: 265-275.

Lozano R, Naghavi M, Foreman K, Lim S, Shibuya K, Aboyans V. 2012. Global and regional mortality from 235 causes of death for 20 age groups in 1990 and 2010: a systematic analysis for the Global Burden of Disease Study 2010. Lancet, 380: 2095-2128.

Magboul AZI, Bashir AK, Khalid SA, Farouk A. 1997. Antimicrobial activity of vernolein and vernodalin. Fitoterapia 68: 8384.

Misra HP, and Fridovich I. 1972. The role of superoxide anion in the autoxidation of epinephrine and a simple assay for superoxide dismutase. J. Biol. Chem. 247: 3170-3175.

Mohamed NA, Shehata MI, El-Sawaf AL., Hussein KH, and Michel TN. 2018. The Ameliorating Effect of Erythropoietin on Diabetic Neurodegeneration by Modulating the AntioxidantOxidant Imbalance and Apoptosis in Diabetic Male Rats. Jordan Journal of Biological Sciences. 11: $339-345$

Mokdad AA, Lopez AD, Shahraz S, Lozano R, Mokdad AH, Stanaway J, et al. 2014. Liver cirrhosis mortality in 187 countries between 1980 and 2010: a systematic analysis. BMC Med. 12: 145.

Muraina IA, Adaudi AO, Mamman M, Kazeem HM, Picard J, McGaw LJ, and Eloff JN. 2010. Antimycoplasmal activity of some plant species from northern Nigeria compared to the currently used therapeutic agent. Pharm. Biol. 48: 1103-1107.
Murray CJL, Vos T, Lozano R, Naghavi M, Flaxman AD, Michaud C, et al. 2012. Disability-adjusted life years (DALYs) for 291 diseases and injuries in 21 regions, 1990-2010: a systematic analysis for the Global Burden of Disease Study 2010. Lancet. 380: 2197-2223.

National Research Council (NRC), 2011. Guide for the care and use of laboratory animals 8th Edition. The National Academies Press.

Oladele JO, Oladele OT, Ademiluyi AO et al. 2020a. Chaya (Jatropha tanjorensis) leafs protect against sodium benzoate mediated renal dysfunction and hepatic damage in rats. Clin Phytosci, 6: 13.

Oladele JO, Oyeleke OM, Awosanya OO, Oladele TO. 2020b. Effect of Curcuma longa (Turmeric) Against Potassium Bromateinduced Cardiac Oxidative Damage, Hematological and Lipid Profile Alterations in Rats. Singapore Journal of Scientific Research, 10: 8-15.

Oladele JO, Oyeleke OM, Oladele OT. et al. 2020c. Nitrobenzene-induced hormonal disruption, alteration of steroidogenic pathway, and oxidative damage in rat: protective effects of Vernonia amygdalina. Clin Phytosci, 6: 15.

Oladele JO, Oyewole OI, Bello OK, Oladele OT. 2017. Hepatoprotective Effect of Aqueous Extract of Telfairia occidentalis on Cadmium Chloride-Induced Oxidative Stress and Hepatotoxicity in Rats. Journal of Drug Design and Medicinal Chemistry. 3(3): 32-36.

Oladunmoye MK, Afolami OI, Oladejo BO, Amoo IA, Osho BI. 2019. Identification and Quantification of Bioactive Compounds Present in the Plant Vernonia amygdalina Delile using GC-MS Technique. Nat Prod Chem Res 7: 356.

Oyewole OI, and Oladele JO. 2017. Changes in Activities of Tissues Enzymes in Rats Administered Ficus exasperata Leaf extract. Int. J. Biol. Chem. Sci. 11(1): 378-386.

Oyewole OI, Oladele JO, and Oladele OT. 2017. Methanolic leaf extract of Ficus Exasperata Leaf attenuates Arsenate-Mediated hepatic and renal oxidative stress in rats. Res. J. of Health Sci. 5(2): 115- 123.

Sahreen S, Khan MR, Khan RA. 2011. Phenolic compounds and antioxidant activities of Rumex hastatus D. Don. Leaves. J Med Plants Res. 5:2755-2765.

US EPA (1996) "Proposed guidelines for carcinogen risk assessment” Federal Register, 61: 17960 - 8011.

Varshney R, and Kale RK. 1990. Effect of calmodulin antagonist on radiation induced lipid peroxidation in microsomes. International Journal of Radiation Biology 58: 733-743.

Wolff SP. 1994. Ferrous ion oxidation in the presence of ferric ion indicator xylenol orange for measurement of hydroperoxides. Methods Enzym. 233: 182-189.

Wu SJ, Lin YH, Chu CC, Tsai YH, Jane CJ. 2008. Curcumin or saikosaponin a improves hepatic antioxidant capacity and protects against CCl4-induced liver injury. Journal of Medicinal Food 11(2): 224-229.

Yang HL, Chen SC, Chang NW, Chang JM, Lee ML, Tsai PC, and Hseu YC. 2006. Protection from oxidative damage using Bidens pilosa extracts in normal human erythrocytes. Food and Chemical Toxicology 44: 1513-1521. 